\title{
Age at maturity in wild baboons: genetic, environmental and demographic influences
}

\author{
M. J. E. CHARPENTIER,$*+J$. TUNG,${ }^{*}$ J. ALTMANN $¥ \S$ and S. C. ALBERTS*§ \\ *Department of Biology, Duke University, PO Box 90338, Durham, NC 27708, USA, +Centre d'Ecologie Fonctionnelle et Evolutive, \\ Unite Mixte de Recherche 5175, Centre National de la Recherche Scientifique, 1919 Route de Mende, 34293 Montpellier Cedex 5, France, \\ $\ddagger$ Department of Ecology and Evolutionary Biology, Princeton University, Princeton, NJ 08540, USA, §Institute of Primate Research, \\ National Museums of Kenya, PO Box 24481, Nairobi, Kenya
}

\begin{abstract}
The timing of early life-history events, such as sexual maturation and first reproduction, can greatly influence variation in individual fitness. In this study, we analysed possible sources of variation underlying different measures of age at social and physical maturation in wild baboons in the Amboseli basin, Kenya. The Amboseli baboons are a natural population primarily comprised of yellow baboons (Papio cynocephalus) that occasionally hybridize with anubis baboons (Papio anubis) from outside the basin. We found that males and females differed in the extent to which various factors influenced their maturation. Surprisingly, we found that male maturation was most strongly related to the proportion of anubis ancestry revealed by their microsatellite genotypes: hybrid males matured earlier than yellow males. In contrast, although hybrid females reached menarche slightly earlier than yellow females, maternal rank and the presence of maternal relatives had the largest effects on female maturation, followed by more modest effects of group size and rainfall. Our results indicate that a complex combination of demographic, genetic, environmental, and maternal effects contribute to variation in the timing of these life-history milestones.
\end{abstract}

Keywords: baboons, first reproduction, hybrids, maternal effects, maturational milestones, menarche

Received 13 July 2007; revision received 28 November 2007; accepted 24 January 2008

\section{Introduction}

Age at maturity can have a large impact on fitness, particularly in expanding populations (Lewontin 1965; reviewed in Roff 1992; Stearns 1992). However, life-history theory postulates that investment in current reproduction imposes costs in terms of the probability of future reproduction and/or survival. That is, initiating reproduction at a relatively young age may be beneficial in that it facilitates the relatively rapid spread of an individual's lineage, but it may also exact a cost in terms of reduced survivorship (Roff 1992; Stearns 1992). The timing of early life-history events, particularly surrounding the age at which an animal begins breeding, therefore has the potential to greatly influence lifetime reproductive output and overall

Correspondence: Marie Charpentier, Department of Biology, Duke University, PO Box 90338, Durham, NC 27708, USA. Fax: +01919 660 7293; E-mail: mariecharp@yahoo.fr fitness (Stearns 1976, 1992). Knowledge of the extent to which these traits vary, and identification of sources of variation in age at maturation, are important for understanding the nature of these trade-offs and their potential fitness consequences.

In this study, we analysed possible sources of variation in age at maturation in female and male yellow baboons (Papio cynocephalus) living in a natural population in the Amboseli basin of southern Kenya. The Amboseli baboon population is part of a larger extended population of baboons in southern Kenya and northern Tanzania; baboons in both Amboseli and the larger population are characterized by high levels of genetic diversity (Loisel et al. 2006) and a general pattern of outbreeding, facilitated by extensive male dispersal within the region (Samuels \& Altmann 1991; Alberts \& Altmann 2001; Storz et al. 2002; S.C. Alberts and J. Altmann, unpublished data). Amboseli in particular is located within a hybrid zone between yellow and anubis (Papio anubis) baboons that runs southwest to northeast across Tanzania 
and Kenya (Maples \& McKern 1967; Kingdon 1971; Samuels \& Altmann 1986; Alberts \& Altmann 2001; Tung et al. 2008). Hence, in addition to previously suggested sources of variance, including social dominance status and demographic effects, we examined the contributions of two additional potential genetic sources of variance - individual heterozygosity and individual history of hybridization which have not been considered in prior analyses.

We considered the potential impact of neutral heterozygosity on maturation scheduling because associations between multilocus heterozygosity and components of fitness have been demonstrated several times in both plant and animal species (Britten 1996; but see Duarte et al. 2003 and references therein documenting no relationship between heterozygosity and fitness correlates). Generally, greater heterozygosity appears to have a beneficial effect on fitnessrelated traits, and exhibits positive correlations with survival (Laikre et al. 1997 and references therein; Coulson et al. 1998, 1999), growth (Coltman et al. 1998; Pujolar et al. 2005), reproductive parameters (Slate et al. 2000; Amos et al. 2001; Charpentier et al. 2005; Hoffman et al. 2004; Seddon et al. 2004), and disease resistance (Acevedo-Whitehouse et al. 2003). Furthermore, mate choice may also be influenced by heterozygosity in potential mates (Mays \& Hill 2004; Hoffman et al. 2007), which could secondarily influence maturation milestones such as age at first reproduction or dispersal.

Our analysis of hybridity was motivated by earlier work in this population based on morphological measurements of hybridity, which suggested that hybrid males disperse earlier than yellow males (Alberts \& Altmann 2001). This raised the possibility that anubis baboon ancestry may contribute to variation in maturation-related traits. While the impact of hybrid ancestry on fitness-related traits such as survival or morphological development has been extensively studied in some systems (Grant \& Grant 1992; Arnold \& Hodges 1995; McClelland \& Naish 2007), the timing of maturation of hybrid individuals has been examined in only a few studies, which have produced mixed outcomes. For example, in Gambusia fishes, hybrids and one parental form exhibited enhanced fitness correlates compared to the second parental form: larger length at birth, earlier maturation, and larger size (Scribner 1993). In contrast, sexual maturation in hybrids between brown trout and brook trout was severely impaired (Blanc \& Chevassus 1986). In Drosophila species, hybrids exhibited intermediate maturation rates (Carracedo et al. 1989).

Hybridization can facilitate evolutionary diversification in both plants and animals, including the evolution of ecological diversity as well as the origin of new species (Arnold 1997; Rieseberg 1997; Arnold 2004; Grant et al. 2005; Schwarz et al. 2005). Hybridization in wild primates has been reported and, to some extent, studied in many species (Brockelman \& Srikosamatara 1984; Marshall \&
Sugardjito 1986; Ciani et al. 1989; Supriatna 1991; Watanabe \& Matsumara 1991; Watanabe et al. 1991a, b; Supriatna et al. 1992; Cheverud et al. 1993; Bynum 2002; Detwiler et al. 2005; Johnson et al. 2005; Arnold \& Meyer 2006; Schillaci et al. 2007). The occurrence of hybridization has been particularly well characterized within the baboon genus Papio (Nagel 1973; Phillips-Conroy \& Jolly 1981, 1986; Alberts \& Altmann 2001; Beehner \& Bergman 2006; Bergman 2006). However, analyses of hybrid performance are rare in wild primate populations (e.g. Alberts \& Altmann 2001; Beehner \& Bergman 2006; Bergman 2006). In this study, we used a quantitative measure of hybridity based on genotype at 14 microsatellite markers dispersed across the baboon genome (Tung et al. 2008) to analyse the potential relationship between maturation timing and genetic hybridity in both sexes.

In previous work on this population, Altmann et al. (1988) found that both age at menarche and age at first reproduction in females were strongly influenced by maternal dominance rank (daughters of higher-ranking females reached menarche earlier and conceived earlier) and that this maternal effect alone resulted in a reproductive advantage for these early maturing females equivalent to roughly half an infant over their lifetimes. Altmann \& Alberts (2005) found that maternal dominance rank actually made two independent contributions to age at menarche. First, daughters of higherranking females grew faster, and faster-growing juveniles reached menarche earlier. Second, maternal dominance rank also made an independent and direct contribution to age at menarche after controlling for the effects of growth rate (Altmann \& Alberts 2005). Like menarche in females, sexual maturity in male baboons (marked by testicular enlargement; Alberts \& Altmann 1995a) was influenced by maternal dominance rank both indirectly (through growth rate) and directly after controlling for growth rate (Altmann \& Alberts 2005), so that sons of higher-ranking mothers matured earlier. Sons of higher-ranking mothers also attained their first adult rank earlier, as did males whose mothers had died during the males' juvenile periods (Alberts \& Altmann 1995a). Maternal rank did not directly influence age at first sexual consortship in males (i.e. first mate guarding episode, a reasonable proxy for age at first reproduction in males; see also Alberts \& Altmann 1995a), because this event was strongly influenced by the availability of reproductive females. However, the earlier rank attainment experienced by sons of high-ranking mothers positioned them to take advantage of these reproductive opportunities at an earlier age because ages at rank attainment and first consortship are highly correlated (Alberts \& Altmann 1995a; see also below). Finally, males whose mothers died in the males' juvenile periods, and males with young mothers, were likely to disperse at younger ages than other males (although age at first dispersal, like age at first sexual consortship, was heavily influenced by the availability of reproductive females; Alberts \& Altmann 1995b). 
In this study, we extend these previous analyses of sources of variance in age at maturity in this population. As maturational milestones, we focused on age at physical maturation (testicular enlargement in males and menarche in females) and age at first attainment of adult rank in both sexes, as well as age at first reproduction in females and age at natal dispersal in males. In addition to individual heterozygosity and hybrid ancestry, we included in our analyses other variables that have previously been associated with maturation in the work discussed above, including those associated with maternal effects and maternal kin, the environment (rainfall), and the demography of social groups in the population (density of adult females or excess of cycling females relative to males, within groups).

\section{Methods}

\section{Study population}

This study focused on wild yellow baboons (Papio cynocephalus) of both sexes living in the Amboseli basin of Kenya. The study population has been the subject of ongoing research for more than three decades, and is described in detail elsewhere (see for example: Hausfater 1975; Altmann 1980; Altmann et al. 1988; Muruthi et al. 1991; Alberts \& Altmann 1995a, b; Altmann et al. 1996; Alberts et al. 2003; Altmann \& Alberts 2003a). All animals in study groups are individually known, and all demographic and life-history events (births, maturation events, immigrations, deaths and emigrations) are recorded on a routine basis as part of daily monitoring in the study groups. In all the following analyses, we excluded the one study group (Lodge group) and its fission products that foraged part-time at a refuse site associated with a tourist lodge. This group experienced an enhanced energetic balance, and consequently accelerated growth and maturation schedules, because of its access to discarded human foodstuffs (Altmann \& Alberts 2005). In addition, no males immigrated into this population during 12 years of intensive monitoring, and natal males emigrated at a reduced rate relative to wild-feeding groups, resulting in increased levels of relatedness between potential mating partners and a probable increase in inbreeding in this group. These features (enhanced energetic balance combined with reduced dispersal, and hence, reduced genetic diversity; Altmann et al. 1996; Alberts 1999) made it a poor candidate for this study.

We analysed variation in the timing of life-history milestones for a total of 242 individuals, comprising 152 females and 90 males. Due to missing data (unknown maturation dates or unknown values of the explanatory variables for some milestones and some individuals), the sample sizes for different statistical models vary.

\section{Male and female life-history patterns}

We first analysed age at physical maturation (testicular enlargement and menarche) separately for males and females. Testicular enlargement was assessed by systematic visual inspection of the scrotal sac each month; before testicular enlargement the scrotum appears as a transverse, concave flap of skin, which rapidly enlarges and become pendulous as the testes enlarge during puberty (see Alberts \& Altmann 1995a for details). Menarche was assessed by daily visual inspection of the sexual skin for evidence of the first sexual swelling (see Altmann et al. 1988; Gesquiere et al. 2007 for details). These life-history milestones signal puberty, and hence, the onset of adulthood for females and of subadulthood (a prolonged period of reproductive inactivity after puberty accompanied by a growth spurt; Alberts \& Altmann 1995a) for males. We then analysed the age at 1st adult rank attainment in both sexes, defined as the age at which an individual consistently began to outrank at least one other adult of the same sex in agonistic interactions (see Alberts \& Altmann 1995a). Rank attainment among adult females occurs gradually during the juvenile period, before the female reaches menarche. The female's rank relative to other adult females then remains quite stable throughout adult life (Silk 1987). By contrast, rank attainment in males occurs rapidly approximately 2 years after testicular enlargement, and coincides with the end of subadulthood and the onset of a period of rapid rise in dominance rank among adult males (Alberts \& Altmann 1995a; see also in P. ursinus: Hamilton \& Bulger 1990). We consider it to signal the beginning of adulthood for males (Alberts \& Altmann 1995a). In males, we also studied age at natal dispersal (females are the philopatric or matrilocal sex in baboons and most other cercopithecine primate species; Pusey \& Packer 1987). Finally, for females, we analysed variation in the age at first reproduction, measured as the age at which females gave birth for the first time to a live offspring. For males, age at first paternity was difficult to assess even with extensive genetically based paternity assignments because infant mortality is high, and first offspring may die before they are sampled for paternity analysis (Buchan et al. 2003; Alberts et al. 2006). Data were available for an alternative measure, age at first consortship for males. However, complete information on all the potential explanatory variables used in these analyses were available for only 21 of these males, limiting the statistical power of the multivariate models we applied to all other milestones. Consequently, although age at first reproduction is an important life-history milestone in males as well as females, we did not analyse variation in any estimate of age at this event. The median and range for male age at first consortship are included in Fig. 1.

In order to analyse sources of variance in age at maturity, we first compiled data on attainment of maturational 

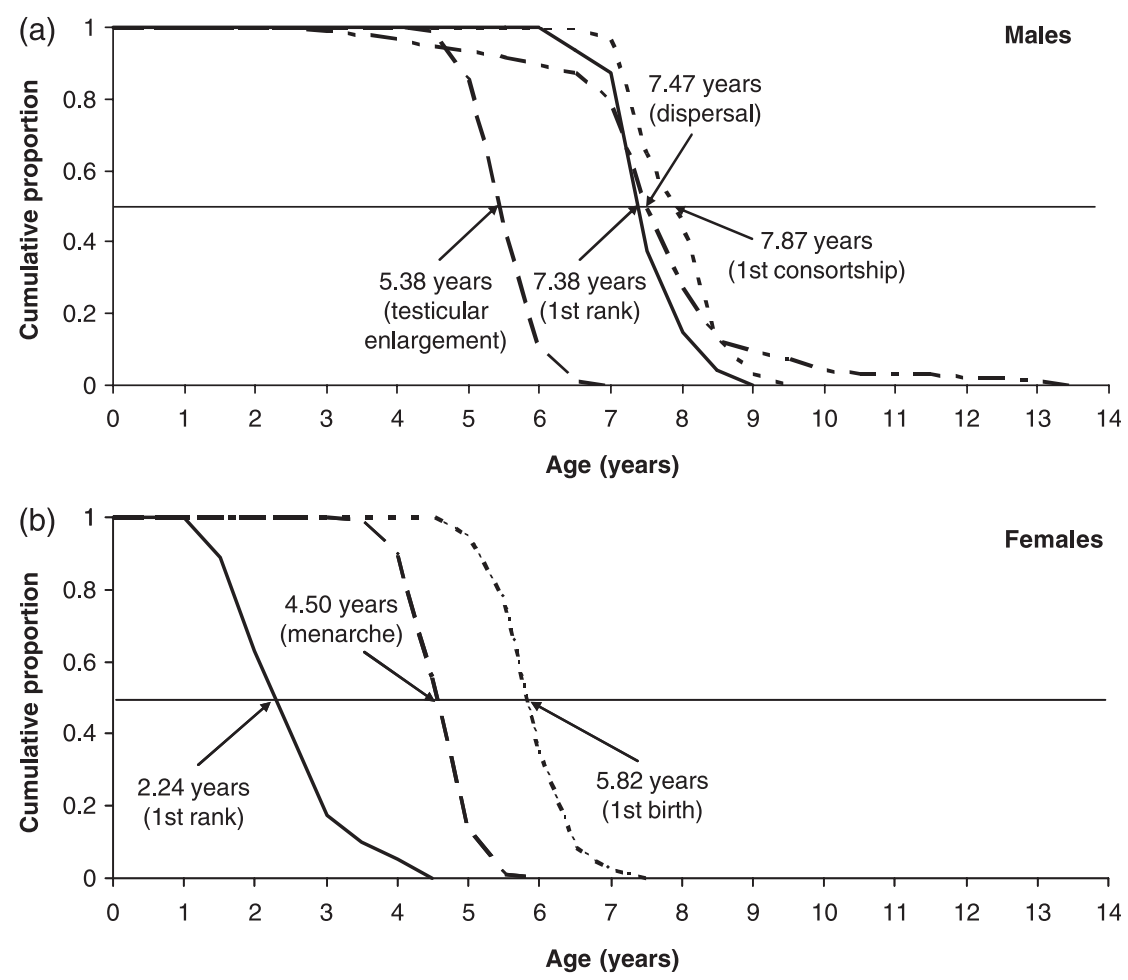

Fig. 1 Failure time graphs for the attainment of maturational milestones as a function of age for (a) males, and (b) females. Note that these sample sizes differ from the ones used in the statistical analyses because the graph includes all individuals from wild-feeding study groups for whom we had maturation information; for some of these we lacked the genetic or environmental information necessary to conduct the multivariate analyses. Arrows point to the median age at which a given milestone was attained in this study. (a) Males. Dashed line, testicular enlargement $(N=96)$; alternated dots and dashes, natal dispersal $(N=93)$; solid line, rank attainment $(N=48)$; dotted line, first consortship $(N=31)$. (b) Females. Dashed line, menarche $(N=174)$; solid line, rank attainment $(N=89)$; dotted line, first reproduction $(N=97)$. milestones in both sexes, extracting these data from the long-term relational database of the Amboseli Baboon Project, BABASE. Figure 1 shows the relationship between age and attainment of the maturational milestones we considered, for both sexes. In males, maturational milestones were attained in a relatively invariant sequence: testicular enlargement always preceded adult rank attainment by at least a year $(N=46$ males for whom both dates are accurately known) and rank attainment virtually always preceded first consortship $(N=27$ males for whom both dates are accurately known; the four cases in which first consortship apparently preceded rank attainment probably result from the high margin of error associated with ascertainment of date of adult rank attainment - a brief and sometimes unobtrusive event - compared to detecting first consortship - a protracted and conspicuous event; in each of these four cases, first consortship was observed at most a few weeks before first rank attainment). In contrast to the predictable sequence of occurrence for testicular enlargement, rank attainment and first consortship, the timing of natal dispersal was quite variable relative to these other milestones - some males dispersed as juveniles; others as subadults, that is, after testicular enlargement but before rank attainment; and others as adults, that is, after rank attainment but either before or after first consortship. The ages at which testicular enlargement, first adult rank, and natal dispersal were attained were significantly positively correlated (Pearson correlations: testicular enlargement, first rank: $N=46$, $r=0.62, \quad P<0.0001 ;$ testicular enlargement, dispersal: $N=79, r=0.32, P=0.004$; rank-dispersal: $N=46, r=0.39$, $P=0.007)$. Therefore, males tended to mature early by all measures, or to mature late by all measures. Because testicular enlargement was significantly correlated with adult rank attainment and always occurred before it, we treated age at testicular enlargement as a covariate in the analysis of age at first adult rank. However, because the relative timing of dispersal varied greatly between males, we did not consider age at testicular enlargement or age at adult rank attainment as covariates in the analysis of age at natal dispersal.

In females, the maturation sequence was invariant: females attained first adult rank, then experienced menarche, and finally gave birth to their first live offspring $(N=41$ females for whom complete data were available for all three lifehistory milestones). Because age at menarche was significantly positively correlated with age at first reproduction (Pearson correlations, menarche-first reproduction: $N=95, r=0.75$, $P<0.0001)$ and always preceded it, we treated age at menarche as a covariate in the analysis of age at first reproduction. However, although age at first adult rank always preceded age at menarche and age at first live birth, age at first adult rank was not correlated with either of the other measures (rank-menarche: $N=76, r=0.16, P=0.16$; rank-first reproduction: $N=41, r=0.14, P=0.37$ ). Therefore, we did not include age at adult rank attainment as a covariate when modelling age at menarche and age at first live birth in females. 


\section{Predictor variables}

We considered three types of genetic and kinship-related sources of variance (neutral heterozygosity, hybridity, and maternal effects/maternal kin) and two types of nongenetic sources of variance (group demography and rainfall) as possible explanatory factors underlying variation in the timing of maturation milestones within the Amboseli baboon population. The full set of explanatory variables are summarized in Table S1 (Supplementary material) and discussed in detail below.

Genetic and kinship-related sources of variance. Up to 14 autosomal polymorphic microsatellite loci were typed in 453 wild-feeding individual baboons, using primers designed for human loci (Buchan et al. 2005; Alberts et al. 2006; Tung et al. 2008). All focal individuals in this maturation study ( $N=152$ females, $N=90$ males) were genotyped at all 14 microsatellite markers, with the exception of five individuals that were genotyped at 13 loci each, and one at 9 loci.

Genetic diversity. We analysed the effect of genetic diversity (neutral heterozygosity) on the focal individuals' age at maturation. As the metric of genetic diversity, we used mean individual heterozygosity measured across all typed microsatellites, $H_{\mathrm{O}}$ (number of heterozygous loci/number of loci genotyped). In the study population as a whole $(N=242)$, mean heterozygosity was high, at $0.817 \pm 0.007$ (sem); the range across individuals was $0.5-1$. To investigate whether our 14 microsatellite loci gave a good picture of genome-wide heterozygosity, we examined the correlation between $H_{\mathrm{O}}$ in two data sets, each containing half of the microsatellites selected randomly from the 14 loci analysed (Balloux et al. 2004). We repeated this analysis 1000 times using sPLus 2000 . We found a significant ' $\mathrm{H}_{\mathrm{O}}-\mathrm{H}_{\mathrm{O}}$ correlation' $(r=0.10, P<0.05)$ indicating that homozygosity at our 14 loci is likely to reflect inbreeding.

Hybridity. We analysed the effect of hybridity on timing of maturation in both sexes using a continuous genetic hybrid score for each individual that ranged in value from 0 (yellow) to 1 (anubis; Tung et al. 2008). This score represents an estimate of the proportion of each individual's genome that is attributable to anubis baboon ancestry, based on genotype at the polymorphic microsatellite loci we analysed. Scores were derived using the admixture analysis implemented in the program structure 2.0 (Pritchard et al. 2000; Falush et al. 2003; see Tung et al. 2008 for details). In our data set, hybridity values ranged from 0.029 to 0.839 (median $=0.10)$. Most scores fell in the lower half of the distribution, with a large cluster near 0 , and only one individual had a genetic hybrid score greater than 0.75 . This distribution suggests that the majority of the population is composed of individuals with predominantly yellow baboon ancestry; a smaller proportion of individuals in the population is hybrid, and only a few individuals are predominantly anubis (Tung et al. 2008). We also had morphological hybrid scores (based on standard morphological assessments; Alberts \& Altmann 2001) and pedigree data (based on parentage analysis; Alberts et al. 2006) for some of the individuals in this analysis (see Tung et al. 2008 for details). We observed good agreement between morphological and genetic hybrid scores $(n=315, r=0.484)$. Permutation tests yielded a significance value of $P<0.0001$ in 10000 permutations, demonstrating that this relationship reflects real concordance between these two metrics. Comparisons of individual genetic hybrid scores with the midpoint values of the parents also showed extremely high consistency within the data set $(n=272, r=0.905 ; P<0.0001$ in 10000 permutations). Therefore, empirical evidence from several sources indicates that our hybrid scores are robust estimates of hybrid ancestry (Tung et al. 2008).

Effects of mothers and other maternal kin. Maternity was unambiguously determined by visual observations of females during successive pregnancies and peri-parturitional events. For evaluation of maternal effects, we first considered the possible impact on offspring of maternal dominance rank at offspring conception, because this is known to influence a number of life-history traits and developmental and social milestones in baboons and other primates (Altmann et al. 1988; Alberts \& Altmann 1995b; Pusey et al. 1997; Bercovitch et al. 2000; Setchell et al. 2002; Altmann \& Alberts 2003b; Johnson 2003; Altmann \& Alberts 2005). Second, we examined the effects of the mother's presence or absence, considered during the month the life-history milestones were reached. As an individual matures, the probability that his or her mother has died increases. This could produce a spurious relationship between mother's presence and the attainment of the maturational milestones; that is, the longer an individual lives, the more likely he or she is to mature and the more likely the mother is to have died. However, if the relationship between maternal presence and maturation were spurious in this way, then the relationship would be stronger for each successive maturational milestone. This was not the case; mother's presence influenced only the first maturational milestone in females, rank attainment, and none of the maturational milestones in males. We therefore considered that the relationship between time and the probability of mother's presence was too weak to be a concern in our analyses. Finally, we studied the effects of the number of mature maternal half-sisters on maturation, also measured during the month the life-history milestones were attained. We considered the number of maternal half-sisters only when at least $75 \%$ of the females present in the group at the same time had a known mother (some females had unknown 
mothers because they were among the first studied females in Amboseli). Because paternal pedigrees were less complete than maternal pedigrees, we did not consider the influence of paternal sisters on life-history traits. We discuss the effect of potential presence elsewhere (Charpentier et al. 2008).

Environmental and demographic sources of variance. Rainfall is a good predictor of food availability and activity budget (Bercovitch \& Strum 1993), both of which may influence maturation. Hence, we included in our models the total amount of rainfall that fell in the 12 months before attainment of the life-history milestone in question. Because maturation schedules may also be influenced by number of potential mates and/or potential competitors, we also evaluated demographic influences on attainment of life-history milestones. Specifically, for female baboons, we measured the number of mature females in the group (density in the group) during the month in which maturity was attained. Group size (measured as number of mature females) is known to negatively influence both fertility and survival for female cercopithecine primates in several populations, probably reflecting feeding competition and/or socially mediated stress effects (Bulger \& Hamilton 1987; Silk 2001; Altmann \& Alberts 2003b). For males, we measured the number of cycling females minus the number of mature males present in the natal group during the month in which physical maturity was attained (i.e. the number of 'excess females' in the group, following Alberts \& Altmann 1995a). For males, the number of excess females is a direct estimate of the intensity of sexual competition he will experience (Alberts \& Altmann 1995b; Altmann 2000). These two demographic variables - number of mature females and number of excess females - were correlated, such that small groups were more likely to have an excess of cycling females and the number of excess males increased with group size ( $r=0.58$ across all data points). Because baboons are large, long-lived mammals, the numbers of adult males and females in a group are relatively stable, changing only slowly over time. Consequently, the value of these variables during the month in which a milestone was attained also reflects demographic conditions for a number of months previous to that month.

\section{Statistical analyses}

Testing assumptions of the model-fitting approach. Before attempting to fit any models to the maturation data, we checked whether any of the explanatory variables we considered exhibited a high degree of codependency. We used the REG procedure implemented in sAs version 9 to evaluate potential collinearities between variables, modelling the pairwise relationship between each of the potential explanatory variables discussed above. In order to fit our data to a normal distribution, four males were removed from the analysis of natal dispersal because three of them dispersed extremely early and one dispersed extremely late (2.58-3.57 years and 12.73 years, respectively). Inclusion of these outliers caused the distribution to be non-normal, violating the assumptions underlying the parametric analyses we used; however, the results of our analyses were qualitatively the same whether or not we included these males. Similarly, one female was removed from the analysis of age at first reproduction because she gave birth for the first time atypically late (8.64 years). Age at first rank in females was log-transformed to fit a normal distribution. We used a Gaussian error structure for all models because the residuals of the maturation analyses were all normally distributed (Kolmogorov-Smirnov test, results not shown).

The results of the preliminary analyses identified collinearity between some of our explanatory variables. For example, heterozygosity values were correlated with hybridity scores. Therefore, we attempted to determine whether these collinearities created confounds in the analyses. To do so, we applied several criteria. First, we checked that no predictor variables were correlated above $r= \pm 0.70$ (Pearson correlation coefficients) for any pairwise combination of variables (following Glantz \& Slinker 2000). Second, because confounding multicollinearities among three or more predictors can exist even when all pairwise correlations are small (Norman \& Streiner 2000), we assessed the severity, number, and structure of multicollinearities. Specifically, we regressed each predictor variable on all remaining predictor variables, and used the $R^{2}$ values from these auxiliary regressions to compute the variance inflation factor, $\mathrm{VIF}=1 /\left(1-R^{2}\right)$ in SAs. As a general rule, models with variables exhibiting VIF $>4$ should not be considered (reviewed in Glantz \& Slinker 2000; Norman \& Streiner 2000), and none of our models had VIF $>4$.

Mixed model analysis. All models were analysed using a mixed model approach (MIXED procedure in SAs), where social group membership was treated as a random effect, to correct for potential random effects due to the group identity. Because each of the study groups shifted its home ranges from poor habitats to better habitats at a discrete point in time during the three decades of study (Bronikowski \& Altmann 1996; Altmann \& Alberts 2003b), we considered the quality of the habitat (before home range shifts: 0, after home range shifts: 1) as an additional random effect. All other variables were treated as fixed effects. We used a backward model selection procedure (Burnham \& Anderson 1998) to select a best-fit set of explanatory variables. Specifically, we started with all potential explanatory effects incorporated into the model, and then removed the effect with the highest $P$ value from the model. We then refit the model to the maturation data and repeated these steps until all $P$ values for individual parameters remaining in the model were less than 0.10 . For all model effects, we set 
Table 1 Effects of genetic, demographic, and environmental explanatory variables on life-history traits in male baboons

\begin{tabular}{|c|c|c|c|c|c|c|}
\hline Milestones & Explanatory variables & $F$ & d.f. & $P$ & $R^{2}$ (percentage) & Direction \\
\hline \multirow[t]{7}{*}{ Testicular enlargement $N=80$} & Mother's presence & 0 & 1,75 & 0.97 & - & - \\
\hline & $\begin{array}{l}\text { Number of } \\
\text { maternal half-sisters }\end{array}$ & 0.17 & 1,75 & 0.68 & - & - \\
\hline & Heterozygosity & 0.11 & 1,78 & 0.75 & - & - \\
\hline & Hybridity & 6.97 & 1,78 & 0.010 & 7.6 & $\begin{array}{l}\text { Earlier maturation } \\
\text { with increasing hybrid score }\end{array}$ \\
\hline & Maternal rank & 7.50 & 1,78 & 0.008 & 8.8 & $\begin{array}{l}\text { Earlier maturation } \\
\text { with higher ranking mothers }\end{array}$ \\
\hline & $\begin{array}{l}\text { Number of } \\
\text { excess females* }\end{array}$ & 3.28 & 1,78 & 0.075 & 3 & $\begin{array}{l}\text { Earlier maturation } \\
\text { with increasing excess females }\end{array}$ \\
\hline & Rainfall & 0.03 & 1,75 & 0.87 & - & - \\
\hline \multirow[t]{8}{*}{ Adult rank $N=36$} & Age at maturation & 33.66 & 1,34 & $<0.0001$ & 36.9 & $\begin{array}{l}\text { Earlier attainment of rank with } \\
\text { earlier physical maturation }\end{array}$ \\
\hline & Mother's presence & 0.34 & 1,34 & 0.57 & - & - \\
\hline & $\begin{array}{l}\text { Number of } \\
\text { maternal half-sisters }\end{array}$ & 0.48 & 1,34 & 0.50 & - & - \\
\hline & Heterozygosity & 0.02 & 1,34 & 0.88 & - & - \\
\hline & Hybridity & 4.14 & 1,34 & 0.053 & 8.4 & $\begin{array}{l}\text { Earlier attainment of rank with } \\
\text { increasing hybrid score }\end{array}$ \\
\hline & Maternal rank & 0.35 & 1,34 & 0.56 & - & - \\
\hline & $\begin{array}{l}\text { Number of } \\
\text { excess females* }\end{array}$ & 1.54 & 1,34 & 0.23 & - & - \\
\hline & Rainfall & 0 & 1,34 & 0.97 & - & - \\
\hline \multirow[t]{7}{*}{ Dispersal $N=73$} & Mother's presence & 0.02 & 1,71 & 0.90 & - & - \\
\hline & $\begin{array}{l}\text { Number of } \\
\text { maternal half-sisters }\end{array}$ & 1.90 & 1,71 & 0.17 & - & - \\
\hline & Heterozygosity & 0 & 1,71 & 0.95 & - & - \\
\hline & Hybridity & 20.03 & 1,71 & $<0.0001$ & 21.6 & $\begin{array}{l}\text { Earlier dispersal with } \\
\text { increasing hybrid score }\end{array}$ \\
\hline & Maternal rank & 1.68 & 1,71 & 0.20 & - & - \\
\hline & $\begin{array}{l}\text { Number of } \\
\text { excess females* }\end{array}$ & 0.62 & 1,71 & 0.44 & - & - \\
\hline & Rainfall & 0.26 & 1,71 & 0.61 & - & - \\
\hline
\end{tabular}

Effects included in the best fit model are shown in bold. Note that d.f. vary because of variation in sample size due to unknown number of maternal half-sisters in a few cases and unknown amount of rainfall for the very last year of the study (2006). *Number of excess females $=$ number of cycling females minus number of mature males.

the threshold for significance at $P<0.05$, but we considered effects with $0.05<P<0.10$ indicative of trends. As a measure of goodness-of-fit, we used the Akaike information criterion (AIC, Akaike 1974). Final models showed, in all cases, the best fit to our data in the sense that they had the lowest AIC values of all models we tested. Full models before model selection are presented in Table S1.

\section{Results}

\section{Milestones in male baboons}

Hybrid ancestry accelerated every maturational milestone we examined in male baboons. Males with higher hybrid scores (higher proportion of anubis ancestry) reached testicular enlargement earlier than yellow males and exhibited a trend towards earlier attainment of first adult rank
(Table 1; Figs 2 and 3). Although this latter relationship was a nonsignificant trend, age at testicular enlargement was also considered as a covariate in this analysis, and it explained $37 \%$ of the total variance in age at first rank attainment (Table 1). Given that hybridity influenced age at testicular enlargement, and that age at testicular enlargement influenced age at first rank, it follows that genetic hybridity had an important effect on both of these early life-history milestones in males. Hybrid males also experienced natal dispersal earlier than yellow males (Table 1, Fig. 4), and this variable was the only significant source of variance in age at natal dispersal in males (21.6\% of the total variance explained). In contrast to hybridity, individual heterozygosity exhibited no significant relationship with any maturational milestone. We also found that maternal rank influenced one milestone (Table 1): sons of higher-ranking mothers exhibited earlier testicular 

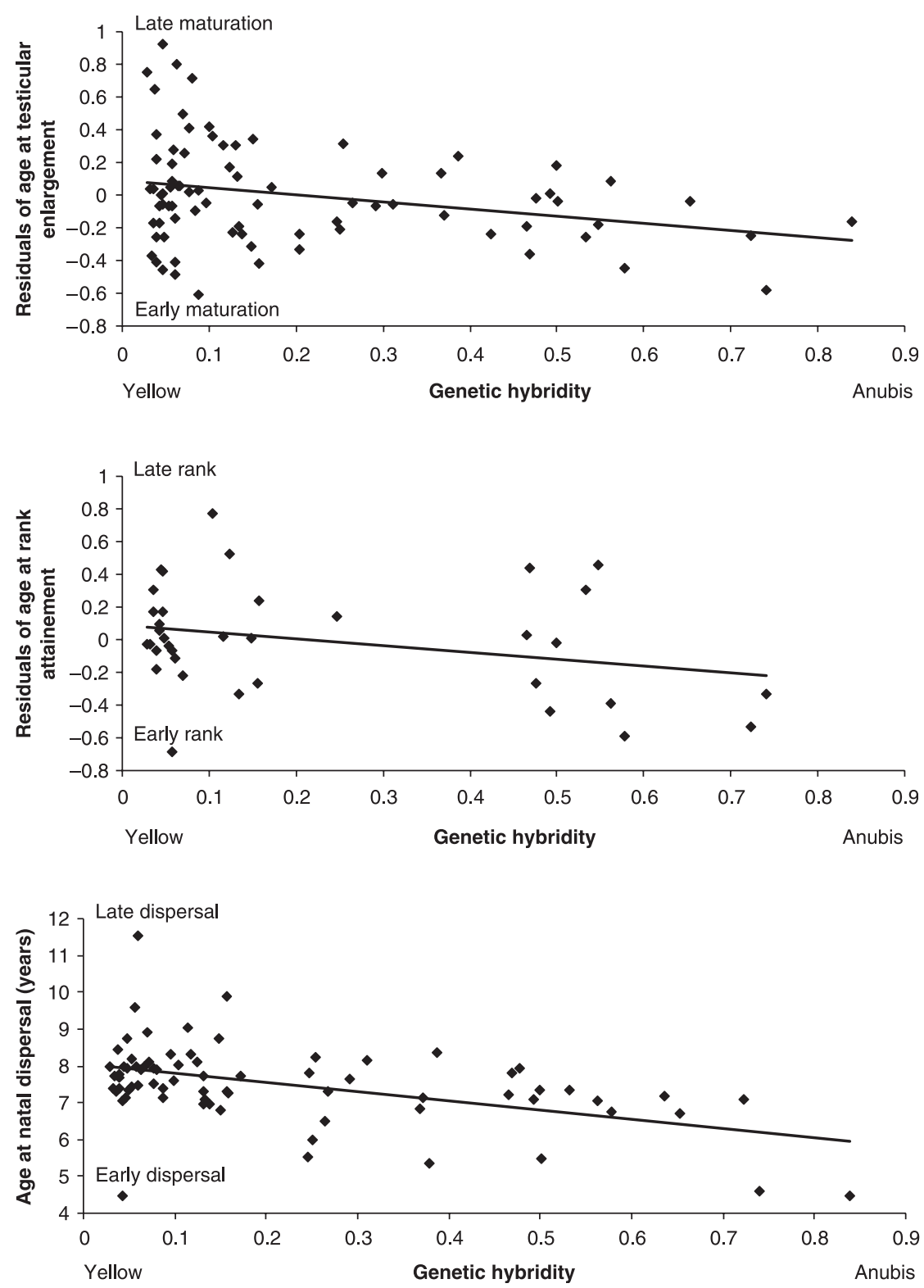

Fig. 2 Age at testicular enlargement in male baboons as a function of genetic hybridity score. The graph represents residuals obtained from a regression that included the other known predictors of this milestone: maternal rank and number of excess females (see Table 2). Negative residuals represent individuals that matured earlier than expected from this equation; positive residuals represent individuals that matured later than expected.

Fig. 3 Age at adult rank attainment in male baboons as a function of genetic hybridity. The graph represents residuals obtained from a regression that included the only significant predictor of this milestone: age at testicular enlargement (see Table 2). Negative residuals represent individuals that ranked earlier than expected from this equation; positive residuals represent individuals that ranked later than expected.

Fig. 4 Age at natal dispersal in male baboons as a function of genetic hybridity. Because genetic hybridity was the only effect in the final model of age at dispersal, we plotted age at dispersal directly as a function of hybrid score. enlargement. Finally, we found a small effect of demographic context on a single maturational milestone: males tended to reach testicular enlargement earlier when their social group contained an excess of cycling females relative to adult males (Table 1). However, this relationship only explained $3 \%$ of the total variance in age at testicular maturation.

\section{Milestones in female baboons}

Females with higher hybrid scores (higher proportion of anubis ancestry) reached menarche earlier, but hybridity explained only $3.7 \%$ of the total variance in age at menarche (Table 2, Fig. 5). It appears that hybridity had relatively little impact on female maturation, especially in comparison to the results for males. Instead, maternal effects and maternal kin had profound consequences for all maturational milestones. Daughters of higher-ranking mothers attained both first adult rank and menarche at earlier ages than daughters of lower-ranking females (Table 2). The mother's death during the juvenile period delayed the age at which females attained their first adult rank (Table 2). Finally, females with more maternal half-sisters present in the group reached menarche earlier (Table 2), suggesting that in some contexts, close maternal kin other than the mother may enhance fitness components in much the same way that a mother does. In addition, we found that age at menarche strongly predicted age at first reproduction in females, with age at menarche explaining $53.1 \%$ of the total variance in timing of first reproduction (Table 2). The physical and demographic environments also influenced maturational 
Table 2 Effects of genetic, demographic, and environmental explanatory variables on life-history traits in female baboons

\begin{tabular}{|c|c|c|c|c|c|c|}
\hline Milestones & Explanatory variables & $F$ & d.f. & $P$ & $R^{2}$ (percentage) & Direction \\
\hline \multirow[t]{7}{*}{$\begin{array}{l}\text { Adult rank } \\
N=97\end{array}$} & Mother's presence & 14.24 & 1,95 & $<0.001$ & 13.2 & $\begin{array}{l}\text { Earlier attainment of rank } \\
\text { with maternal presence }\end{array}$ \\
\hline & $\begin{array}{l}\text { Number of } \\
\text { maternal half-sisters }\end{array}$ & 1.81 & 1,95 & 0.18 & - & - \\
\hline & Heterozygosity & 1.71 & 1,95 & 0.19 & - & - \\
\hline & Hybridity & 0.45 & 1,95 & 0.51 & - & - \\
\hline & Maternal rank & 20.65 & 1,95 & $<0.0001$ & 17.8 & $\begin{array}{l}\text { Earlier attainment of rank } \\
\text { with higher maternal rank }\end{array}$ \\
\hline & $\begin{array}{l}\text { Number of } \\
\text { mature females }\end{array}$ & 0.14 & 1,95 & 0.71 & - & - \\
\hline & Rainfall & 3.90 & 1,95 & 0.052 & 3.3 & $\begin{array}{l}\text { Earlier attainment of rank } \\
\text { with increasing rainfall }\end{array}$ \\
\hline Menarche & Mother's presence & 0.15 & 1,125 & 0.70 & - & - \\
\hline \multirow[t]{6}{*}{$N=127$} & $\begin{array}{l}\text { Number of } \\
\text { maternal half-sisters }\end{array}$ & 7.95 & 1,125 & 0.002 & 7.4 & $\begin{array}{l}\text { Earlier maturation with } \\
\text { more maternal half-sisters }\end{array}$ \\
\hline & Heterozygosity & 0.28 & 1,125 & 0.60 & - & - \\
\hline & Hybridity & 7.20 & 1,125 & 0.008 & 3.7 & $\begin{array}{l}\text { Earlier maturation with } \\
\text { increasing hybrid score }\end{array}$ \\
\hline & Maternal rank & 5.22 & 1,125 & 0.024 & 3.9 & $\begin{array}{l}\text { Earlier maturation with } \\
\text { higher maternal rank }\end{array}$ \\
\hline & $\begin{array}{l}\text { Number of } \\
\text { mature females }\end{array}$ & 6.72 & 1,125 & 0.011 & 3.1 & $\begin{array}{l}\text { Earlier maturation with } \\
\text { decreasing number of females }\end{array}$ \\
\hline & Rainfall & 5.06 & 1,125 & 0.027 & 3.8 & $\begin{array}{l}\text { Earlier maturation with } \\
\text { increasing rainfall }\end{array}$ \\
\hline \multirow[t]{8}{*}{$\begin{array}{l}\text { First reproduction } \\
N=89\end{array}$} & Age at menarche & 102.79 & 1,87 & $<0.0001$ & 53.1 & $\begin{array}{l}\text { Earlier reproduction with } \\
\text { earlier menarche }\end{array}$ \\
\hline & Mother's presence & 1.28 & 1,87 & 0.26 & - & - \\
\hline & $\begin{array}{l}\text { Number of } \\
\text { maternal half-sisters }\end{array}$ & 0.05 & 1,83 & 0.83 & - & - \\
\hline & Heterozygosity & 0.30 & 1,87 & 0.58 & - & - \\
\hline & Hybridity & 0.24 & 1,87 & 0.62 & - & - \\
\hline & Maternal rank & 0.05 & 1,87 & 0.83 & - & - \\
\hline & $\begin{array}{l}\text { Number of } \\
\text { mature females }\end{array}$ & 5.76 & 1,87 & 0.019 & 4.5 & $\begin{array}{l}\text { Earlier reproduction with } \\
\text { decreasing number of females }\end{array}$ \\
\hline & Rainfall & 1.62 & 1,87 & 0.21 & - & - \\
\hline
\end{tabular}

Effects included in the best fit model are shown in bold. Note that d.f. vary because of variation in sample size due to unknown number of maternal half-sisters in a few cases and unknown amount of rainfall for the very last year of the study (2006).

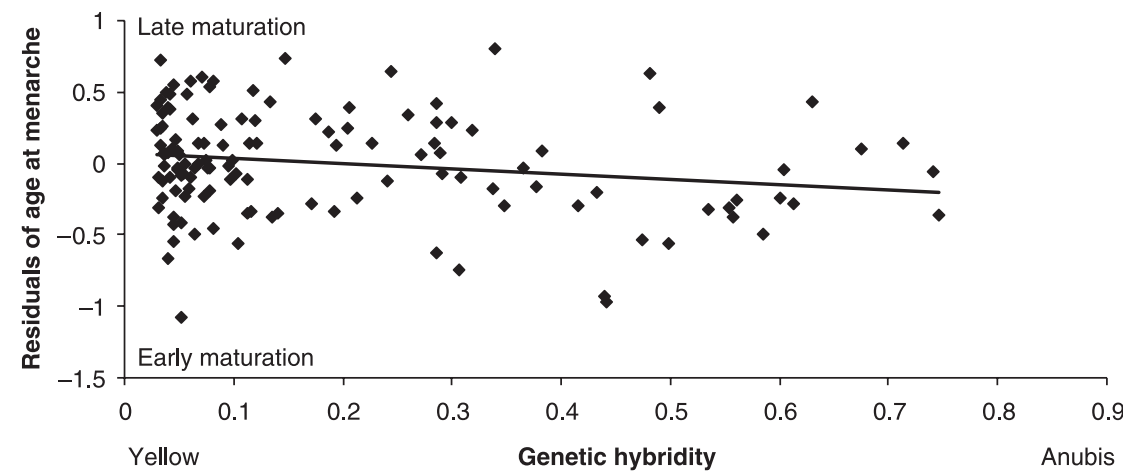

Fig. 5 Age at menarche in female baboons as a function of genetic hybridity. The graph represents residuals obtained from a regression that included the other known predictors of this milestone: number of maternal half-sisters, maternal rank, rainfall in the previous year, and number of mature females within the group (see Table 2). Negative residuals represent individuals that reached menarche earlier than expected from this equation; positive residuals represent individuals that reached menarche later than expected. milestones in females. Females reached menarche earlier, and showed a trend towards achieving earlier first adult rank, when rainfall in the previous year had been relatively high (Table 2). Females also reached menarche and gave birth earlier in groups characterized by relatively few mature females, reflecting the negative density dependence of female fertility that characterizes this population (Table 2 and Altmann \& Alberts 2003b). 


\section{Discussion}

The results of this study highlight how variation in genetic, environmental, demographic, and maternal effects act together to influence variation in the timing of early lifehistory traits in male and female baboons. Most of the best-fit models we identified contained multiple effects, and different maturational milestones were explained by slightly different sets of variables. However, the strong correlations between milestones, the invariant sequences in which milestones were attained (with the exception of natal dispersal in males), and the consistent pattern of explanatory factors within, but not between sexes, indicates the presence of strong maturation syndromes within each sex.

These syndromes are illustrated by a few highly consistent relationships across milestones within sexes. In males, hybrid ancestry had a pervasive effect, such that male baboons with a greater proportion of inferred anubis ancestry reached sexual maturity, achieved first adult rank, and dispersed earlier from their natal group than yellow baboons. This effect of hybrid ancestry is consistent with the fact that testicular size and development are known to vary across baboon species (Zinner et al. 2005; Jolly \& Phillips-Conroy 2006), although no comparative data is available for ages of male maturational milestones in other species. By contrast, maternal effects were the most powerful predictors of maturity in females, predicting age at rank attainment and age at menarche (and consequently age at first birth). The strong influence of maternal effects on female life history is a general phenomenon in cercopithecine primates; mothers directly and indirectly influence their daughters' physical maturation and social status (reviewed in Walters \& Seyfarth 1987; Alberts \& Altmann 2006). We also found an effect of rainfall (a predictor of food availability; Alberts et al. 2005) on menarche, such that female baboons reached menarche earlier after particularly rainy years; they tended to attain rank earlier after rainy years as well. However, the consistently strong maternal effects that females experience may be powerful enough to obscure the effects of some other variables except in large samples. This may account for the relatively modest effect of hybridity on only a single measure of female maturity, age at menarche.

We did not find such strong maternal effects on males in this study (see also Alberts \& Altmann 1995b; Altmann \& Alberts 2005). In previous analyses (Alberts \& Altmann 1995b), we found that high maternal rank accelerated adult rank attainment for males, as well as testicular enlargement, while in this, study we detected only an effect on testicular enlargement. In previous studies, we also found that the mother's death during the male's juvenile period accelerated adult rank attainment as well as natal dispersal; no such effects were found in this study. The difference between this analysis and previous analyses may reflect the fact that, as the number of yellow-anubis hybrids in this popu- lation has increased over time (Alberts \& Altmann 2001; Tung et al. 2008), the strong effects of anubis ancestry on these maturational milestones have swamped the influence of maternal effects in males.

These striking differences between males and females suggest again that the factors underlying life-history trade-offs and reproductive investment differ substantially between the two sexes. It is important to note that sets of influences may differ not only in identity, but also in kind: in this case, maternal effects are of paramount importance in females (maternal rank is a strongly inherited maternal effect), whereas conventional genetic effects are the most consistent factors influencing maturation in males. This situation creates the observed trade-off, in which maternal effects seem to attenuate the influence of genetic hybridity in one sex, but genetic hybridity similarly seems to attenuate maternal effects in the other sex. These results represent a unique, but rarely acknowledged, type of gene by sex interaction effect.

Interestingly, we identified no significant effects of individual heterozygosity for any measure, in spite of a significant, although modest, positive correlation between hybridity and heterozygosity (Spearman rank correlation: $N=440, r=0.31, P<0.0001)$. This result suggests that genetic diversity and heterozygote advantage per se do not account for the effect of hybridity that we have reported here. Instead, we have identified a genetic background effect, whereby either anubis ancestry or the combination between anubis and yellow ancestry contributes to accelerated maturation schedules in male baboons.

\section{Potential mechanisms underlying the relationship between hybridity and maturation}

We identified a significant effect of hybridity on maturation in four of the six measures we used, and the effects of hybrid ancestry were particularly pervasive in males, such that hybrid males matured earlier than yellow males in all three milestones we analysed. One possible explanation for this is heterosis, or hybrid vigor, an increase in fitness among hybrids such that hybrids are superior to both of the parents (Falconer \& Mackay 1996; Kohn et al. 2001; reviewed in Arnold \& Hodges 1995). An interpretation of heterosis would be supported if hybrids mature earlier than both parental phenotypes, and if earlier maturation resulted in higher lifetime fitness. Alternatively, hybrids may represent intermediate fitness phenotypes between two parental populations, exhibiting hybrid advantage over one parent species but not over both. This interpretation would be supported if hybrids matured at intermediate ages relative to the two parental phenotypes and if this intermediate maturation resulted in intermediate fitness.

As a first attempt to differentiate between a heterotic vs. a hybrid intermediacy hypothesis in accounting for our results, we performed an additional test for a quadratic 
effect of hybridity by adding a squared term of the genetic hybrid score in the multivariate analysis. A quadratic effect would suggest that the decrease in age at maturation with hybridity is not linear, potentially signifying heterosis in yellow-anubis hybrids depending on the sign of the quadratic term. No quadratic effect was detected for any of the four maturational milestones in which hybridity played a significant role (results not shown), suggesting that hybrids represent intermediate phenotypes between yellow and anubis baboons. Although these results are suggestive, we are cautious about making strong inferences in favour of one hypothesis vs. the other. In particular, our attempts to fit quadratic curves were limited by small sample size on the upper end of the distribution. Ultimately, in order to differentiate unambiguously between heterosis and hybrid intermediacy in Amboseli, we would need both phenotypic and lifetime fitness data for the anubis populations that send immigrants to Amboseli, as well as for the Amboseli baboons. Such data for anubis populations are not currently available, and the source population for anubis immigrants into Amboseli is unknown, although we suspect that they come from the anubis population on nearby Mount Kilimanjaro (Samuels \& Altmann 1986; Alberts \& Altmann 2001).

Prevailing evidence from several other studies of Papio hybrids also supports a hypothesis of hybrid intermediacy for most phenotypes. First, all five (sub)species within Papio interhybridize and produce viable, fertile offspring where species ranges meet, with no apparent evidence of dysgenesis or heterosis from population-level surveys (see discussions in Jolly 1993; Newman et al. 2004). Second, in the well-studied anubis-hamadryas hybrid population in the Awash National Park, Ethiopia, hybrids are generally morphologically intermediate between the parents (Phillips-Conroy \& Jolly 1981), as are the yellow-anubis hybrids in Amboseli (Alberts \& Altmann 2001). Specifically, hybrid hamadryasanubis males in Ethiopia are closer to hamadryas male size but hybrid females are more anubis-like, resulting in a less pronounced sexual dimorphism in hybrids compared to both subspecies (Phillips-Conroy \& Jolly 1981). Finally, Ackermann et al. (2006) assessed 39 morphological characteristics - primarily cranio-facial measures - of hybrid yellow-anubis baboons with known pedigrees at the Southwest Foundation for Biomedical Research. Anubis and yellow baboons differed significantly on $1 / 3$ of these 39 traits. Among hybrids, intermediate phenotypes between the two parental forms were generally the norm for the traits that differed; only one trait was significantly larger in hybrids than in the parental types, and two were dysgenic phenotypes (Ackermann et al. 2006). These latter results also showed that hybridization may have different effects on different traits.

The hypothesis of hybrid intermediacy for yellow and anubis baboons is also in accord with a hypothesis proposed by C. J. Jolly (personal communication), which posits that anubis baboons represent the most invasive species in the Papio complex, and that anubis genes are introgressed widely into other Papio species, particularly yellow baboons. In other words, Jolly proposes that anubis male baboons repeatedly and successfully immigrate into yellow populations, swamping some of these populations to the extent that they become phenotypically anubis while retaining mtDNA sequences from their yellow female forebears. This is consistent with the pattern described by Newman et al. (2004) and Wildman et al. (2004) in which, among the five major Papio groups, only anubis baboons lacked mtDNA sequences unique to their species; in particular, all mtDNA sequences identified in Kenyan anubis baboons also occurred in Kenyan yellow baboons, while the reverse was not true (Newman et al. 2004, Fig. 2). Newman and colleagues posited local gene flow between yellow and anubis baboons in East Africa to create this pattern, specifically sex-biased gene flow from anubis to yellow populations (Newman et al. 2004). Our results - that hybrid males, and to a lesser extent hybrid females, mature earlier than their yellow counterparts - are consistent with a scenario in which anubis males immigrate into yellow populations and they and their hybrid offspring experience a reproductive advantage relative to yellow baboons. To fully test Jolly's 'invasive anubis' hypothesis, both phenotypic and lifetime fitness data on the anubis populations surrounding Amboseli and complete lifetime reproductive success data for hybrid and yellow individuals within Amboseli are necessary. The results reported here set the stage for such a comprehensive analysis of components of fitness for hybrid compared with yellow baboons in Amboseli.

Although intermediate hybrid life-history phenotypes are consistent with Jolly's 'invasive anubis' hypothesis, the question remains as to why, if earlier maturation enhances reproductive success as expected, anubis baboons have not spread more rapidly into the yellow baboon species range, including Amboseli. One potential explanation is that anubis and yellow populations are separated by geographical distances and/or semi barriers (such as tree-less, waterless expanses of savannah) that make anubis immigration into yellow populations a relatively rare event (see discussion in Tung et al. 2008). Alternatively, if the anubis males that do reach Amboseli represent an extreme maturing phenotype (earlier maturation and dispersal), the tendency towards early maturation in Amboseli hybrids described here may not reflect a general pattern of relative fitness across these baboon species, but instead a heritable propensity for earlier maturation and dispersal in the particular offspring of these early dispersing immigrants. If this were so, the earlier maturation of hybrid Amboseli baboons would reflect a benefit that resulted from being the offspring of particularly early maturing anubis baboons, but not a consequence of hybridity per se. Williams-Blangero \& Blangero (1995) demonstrated that age at first birth in 
captive anubis baboons was indeed highly heritable $\left(h^{2}=0.87\right)$. Finally, the relationships we have reported may actually be due to heterosis within a climate-related ecological cline, not hybrid intermediacy. Darker pelaged anubis baboons are generally associated with higher elevation and cooler climates than those in which many yellow baboons are found (Kingdon 1997): Amboseli may then represent a boundary condition in which individuals of mixed ancestry tolerate heat stress better than their anubis parents (W. Porter and W. Klousie, personal communication), but have an advantage in timing of maturation over their yellow baboon parents. Finally, if we were to observe Amboseli over a sufficiently long time period, we might see that the hybridization documented here represents the beginning of an invasive wave of anubis immigrants that will leave behind it, in future millenia, a phenotypically anubis population in Amboseli, albeit one characterized by the yellow mtDNA haplotypes present there today.

\section{Conclusions}

This study demonstrates that a complex mix of maternal effects, abiotic environment, demographic environment, and genetic background all impacted the timing of important, fitness-related milestones of maturation, such that males and females were subject to different balances among the sets of influences. Females were more constrained by the stable matrilineal hierarchies into which they were born; therefore, the effects of genetic background were muted, in females, by maternal and kinship effects and by resource availability. For males on the other hand, individual genetic background had a much larger influence and maternal effects were more muted. As a result, a female's sons may differ from each other much more than her daughters in age at physical and social maturation, because of the genetic contribution made by different fathers. This illustrates the interesting point that maternal factors may modify the influence of the genetic contributions and therefore the evolutionary consequences of hybridity. For instance, if maternal effects were as strong for the dispersing sex as they were for the matrilocal sex in our study, the 'invasive' tendencies of the earlier-maturing parental type would be attenuated compared to the situation we propose here. Details of the manner in which these genetic and maternal factors contribute to the evolutionary consequences of hybridization represent an important subject for future research.

\section{Acknowledgements}

We thank the Office of the President, Republic of Kenya; the Kenya Wildlife Service, especially the Amboseli staff and Wardens; and the Institute of Primate Research and the National Museums of Kenya for supporting ongoing field research on the Amboseli baboons. Particular thanks go to the Amboseli fieldworkers who contributed to data collection for this project, especially R. Mututua, S. Sayialel, and K. Warutere. We thank Clifford J. Jolly for important discussions about his invasive anubis hypothesis and permission to discuss it in the manuscript. Authors are also very grateful to Franck Prugnolle for his valuable help in programming for data analysis. M. J. E. C. is currently supported by a Marie-Curie Outgoing Fellowship; J.T. is supported by an NSF Graduate Research Fellowship. Research in Amboseli was supported by National Science Foundation grants BCS-0323553 and IOB-0322613 (to S.C.A), and by NSF IOB-0322781 and BCS-0323596 (to J.A).

\section{References}

Acevedo-Whitehouse K, Gulland F, Grieg D, Amos W (2003) Inbreeding: disease susceptibility in California sea lions. Nature, $422,35$.

Ackermann RR, Rogers J, Cheverud JM (2006) Identifying the morphological signatures of hybridization in primate and human evolution. Journal of Human Evolution, 51, 632-645.

Akaike H (1974) A new look at the statistical model identification. IEEE Transactions on Automatic Control, 19, 716-723.

Alberts SC (1999) Paternal kin discrimination in wild baboons. Proceedings of the Royal Society B:Biological Sciences, 266, 15011506.

Alberts SC, Altmann J (1995a) Balancing costs and opportunities: dispersal in male baboons. American Naturalist, 145, 279-306.

Alberts SC, Altmann J (1995b) Preparation and activation: determinants of age at reproductive maturity in male baboons. Behavioral Ecology and Sociobiology, 36, 397-406.

Alberts SC, Altmann J (2001) Immigration and hybridization patterns of yellow and anubis baboons in and around Amboseli, Kenya. American Journal of Primatology, 53, 139-154.

Alberts SC, Altmann J (2006) The evolutionary past and the research future: environmental variation and life history flexibility in a primate lineage. In: Reproduction and Fitness in Baboons: Behavioral, Ecological and Life History Perspectives (eds Swedell L, Leigh S), pp. 277-303. Springer, New York.

Alberts SC, Watts HE, Altmann J (2003) Queuing and queuejumping: long term patterns of reproductive skew among male savannah baboons. Animal Behaviour, 65, 821-840.

Alberts SC, Hollister-Smith J, Mututua RS et al. (2005) Seasonality and long-term change in a savannah environment. In: Seasonality in Primates: Studies of Living and Extinct Human and Non-Human Primates (eds Brockman DK, van Schaik CP), pp. 157-196. Cambridge University Press, Cambridge, UK.

Alberts SC, Buchan JC, Altmann J (2006) Sexual selection in wild baboons: from mating opportunities to paternity success. Animal Behaviour, 72, 1177-1196.

Altmann J (1980) Baboon Mothers and Infants. Harvard University Press, Cambridge, Massachusetts.

Altmann J (2000) Models of outcome and process: Predicting male distribution among primate groups. In: Primate Males: Causes and Consequences of Variation in Group Composition (ed. Kappeler P), pp. 236-247. Cambridge University Press, New York.

Altmann J, Alberts SC (2003a) Variability in reproductive success viewed from a life-history perspective in baboons. American Journal of Human Biology, 15, 401-409.

Altmann J, Alberts SC (2003b) Intraspecific variability in fertility and offspring survival in a non-human primate: behavioral control of ecological and social sources. In: Offspring: The Biodemography 
of Fertility and Family Behavior (eds Wachter KW, Bulatao RA), pp. 140-169. National Academy Press, Washington, DC.

Altmann J, Alberts SC (2005) Growth rates in a wild primate population: ecological influences and maternal effects. Behavioral Ecology and Sociobiology, 57, 490-501.

Altmann J, Alberts SC, Haines SA et al. (1996) Social structure predicts genetic structure in a wild primate group. Proceedings of the National Academy of Sciences, USA, 93, 5797-5801.

Altmann J, Hausfater G, Altmann SA (1988) Determinants of reproductive success in savannah baboons Papio cynocephalus. In: Reproductive Success (ed. Clutton-Brock TH), pp. 403-418. University of Chicago Press, Chicago.

Amos W, Worthington Wilmer J, Fullard Ket al. (2001) The influence of parental relatedness on reproductive success. Proceedings of the Royal Society B: Biological Sciences, 268, 2021-2027.

Arnold ML (1997) Natural Hybridization and Evolution. Oxford University Press, Oxford, UK.

Arnold ML (2004) Natural hybridization and the evolution of domesticated, pest and disease organisms. Molecular Ecology, 13, 997-1007.

Arnold ML, Hodges SA (1995) Are natural hybrids fit or unfit relative to their parents? Trends in Ecology \& Evolution, 10, 67-71.

Arnold ML, Meyer A (2006) Natural hybridization in primates: one evolutionary mechanism. Zoology, 109, 261-276.

Balloux F, Amos W, Coulson T (2004) Does heterozygosity estimate inbreeding in real populations? Molecular Ecology, 13, 3021-3031.

Beehner JC, Bergman TJ (2006) Female behavioral strategies of hybrid baboons in the Awash National Park, Ethiopia. In: Reproduction and Fitness in Baboons. Behavioral, Ecological, and Life History Perspectives (eds Swedell L, Leigh SR), pp. 53-79. Springer, New York.

Bercovitch FB, Strum SC (1993) Dominance rank, resource availability, and reproductive maturation in female savanna baboons. Behavioral Ecology and Sociobiology, 33, 313-318.

Bercovitch FB, Widdig A, Nürnberg P (2000) Maternal investment in rhesus macaques (Macaca mulatta): reproductive costs and consequences of raising sons. Behavioral Ecology and Sociobiology, 48, 1-11.

Bergman TJ (2006) Hybrid baboons and the origins of the hamadryas male reproductive strategy. In: Reproduction and Fitness in Baboons. Behavioral, Ecological, and Life History Perspectives (eds Swedell L, Leigh SR), pp. 81-103. Springer, New York.

Blanc JM, Chevassus B (1986) Survival, growth and sexual maturation of the tiger trout hybrid (Salmo trutta $q \times$ Salvelinus fontinalis ô). Aquaculture, 52, 59-69.

Britten HB (1996) Meta-analyses of the association between multilocus heterozygosity and fitness. Evolution, 50, 2158-2164.

Brockelman WY, Srikosamatara S (1984) Maintenance and evolution of social structure in gibbons. In: The Lesser Ape (eds Preuschof $\mathrm{H}$, Chivers DJ, Brockelman WY, Creel N), pp. 298-323. Edinburgh University Press, Edinburgh, UK.

Bronikowski A, Altmann J (1996) Foraging in a variable environment: weather patterns and the behavioral ecology of baboons. Behavioral Ecology and Sociobiology, 39, 11-25.

Buchan JC, Alberts SC, Silk JB, Altmann J (2003) True paternal care in a multi-male primate society. Nature, 425, 179-181.

Buchan JC, Archie EA, Van Horn RC, Moss CJ, Alberts SC (2005) Locus effects and sources of error in non-invasive genotyping. Molecular Ecology Notes, 5, 680-683.

Bulger J, Hamilton WJ III (1987) Rank and density correlates of inclusive fitness measures in a natural chacma baboon (Papio ursinus) troop. International Journal of Primatology, 8, 635-650.
Burnham KP, Anderson DR (1998) Model Selection and Inference. Springer-Verlag, New York.

Bynum N (2002) Morphological variation within a macaque hybrid zone. American Journal of Physical Anthropology, 118, 4549.

Carracedo MC, Garcia-Florez L, San Miguel E (1989) Sexual maturation in Drosophila melanogaster females and hybridization with $D$. simulans males: a study of inheritance modes. Journal of Heredity, 80, 157-158.

Charpentier M, Setchell JM, Knapp L et al. (2005) Genetic diversity and reproductive success in mandrills (Mandrillus sphinx). Proceedings of the National Academy of Sciences, USA, 102, 1672316728.

Charpentier MJE, van Horn RC, Altmann J, Alberts SC (2008) Paternal effects on offspring fitness in a multimale society. Proceedings of the National Academy of Sciences, USA, 105, 1988-1992.

Cheverud JM, Jacobs SC, Moor AJ (1993) Genetic differences among subspecies of the saddle-back tamarin (Saguinas fuscicollis): evidence from hybrids. American Journal of Primatology, 21, 1-15.

Ciani AC, Stanyon R, Scheffrahn W, Sampurno B (1989) Evidence of gene flow between Sulawesi macaques. American Journal of Primatology, 17, 257-270.

Coltman DW, Bowen WD, Wright JM (1998) Birth weight and neonatal survival of harbour seal pups are positively correlated with genetic variation measured by microsatellites. Proceedings of the Royal Society B: Biological Sciences, 265, 803-809.

Coulson TN, Pemberton JM, Albon SD et al. (1998) Microsatellites reveal heterosis in red deer. Proceedings of the Royal Society B: Biological Sciences, 267, 489-495.

Coulson TN, Albon SD, Slate J, Pemberton JM (1999) Microsatellite loci reveal sex-dependent responses to inbreeding and outbreeding in red deer calves. Evolution, 53, 1951-1960.

Detwiler KM, Burrell AS, Jolly CJ (2005) Conservation implications of hybridization in African cercopithecine monkeys. International Journal of Primatology, 26, 661-684.

Duarte LC, Bouteiller C, Fontanillas P et al. (2003) Inbreeding in the greater white-toothed shrew, Crocidura russula. Evolution, 57, 638-645.

Falconer DS, Mackay TFC (1996) Introduction to Quantitative Genetics, 4th edn. Longman Group, Essex, England.

Falush D, Stephens M, Pritchard JK (2003) Inference of population structure using multilocus genotype data: linked loci and correlated allele frequencies. Genetics, 164, 1567-1587.

Gesquiere LR, Wango EO, Alberts SC, Altmann J (2007) Mechanisms of sexual selection: sexual swellings and estrogen concentrations as fertility indicators and cues for male consort decisions in wild baboons. Hormones and Behavior, 51, 114-125.

Glantz SA, Slinker BK (2000) Primer of Applied Regression and Analysis of Variance, 2nd edn. McGraw-Hill, New York.

Grant PR, Grant R (1992) Hybridization of bird species. Science, 256, 193-197.

Grant PR, Grant BR, Petren K (2005) Hybridization in the recent past. American Naturalist, 166, 56-67.

Hamilton WJ III, Bulger J (1990) Natal male baboon rank rises and successful challenges to resident alpha males. Behavioral Ecology and Sociobiology, 26, 357-362.

Hausfater G (1975) Dominance and Reproduction in Baboons: A Quantitative Analysis. S. Karger, Basel, Switzerland.

Hoffman JI, Boyd IL, Amos W (2004) Exploring the relationship between parental relatedness and male reproductive success in the antartic fur seal Arctocephalus gazella. Evolution, 58, 2087-2099. 
Hoffman JI, Forcada J, Trathan PN, Amos W (2007) Female fur seals show active choice for males that are heterozygous and unrelated. Nature, 445, 912-914.

Johnson SE (2003) Life history and the competitive environment: trajectories of growth, maturation, and reproductive output among chacma baboons. American Journal of Physical Anthropology, 120, 83-98.

Johnson SE, Gordon AD, Stumpf RM, Overdorff DJ, Wright PC (2005) Morphological variation in populations of Eulemur albocollaris and E. fulvus rufus. International Journal of Primatology, 26, 1399-1416.

Jolly CJ (1993) Species, subspecies, and baboon systematics. In: Species, Species Concepts, and Primate Evolution (eds Kimbel WH, Martin LB), pp. 67-107. Plenum Press, New York.

Jolly CJ, Phillips-Conroy JE (2006) Testicular size, developmental trajectories, and male life history strategies in four baboon taxa. In: Reproduction and Fitness in Baboons: Behavioral, Ecological and Life History Perspectives (eds Swedell L, Leigh S), pp. 257-275. Springer, New York.

Kingdon J (1971) East African Mammals. An Atlas of Evolution in Africa. Academic Press, London, UK.

Kingdon J (1997) The Kingdon Field Guide to African. Mammals. Plenum Press, San Diego, California.

Kohn LA, Langton LB, Cheverud JM (2001) Subspecific genetic differences in the saddle-back tamarin (Saguinus fuscicollis) postcranial skeleton. American Journal of Primatology, 54, 41-56.

Laikre L, Ryman N, Lundh NG (1997) Estimated inbreeding in a small, wild muskox Ovibos moschatus population and its possible effects on population reproduction. Biological Conservation, 79, 197-204.

Lewontin RC (1965) Selection for colonizing ability. In: The Genetics of Colonizing Species (eds Baker HG, Stebbins GL), pp. 79-94. Academic Press, New York.

Loisel DA, Rockman MV, Wray GA, Altmann J, Alberts SC (2006) Ancient polymorphism and functional variation in the primate MHC-DQA1 5'-cis-regulatory region. Proceedings of the National Academy of Sciences, USA, 103, 16331-16336.

Maples WR, McKern TW (1967) A preliminary report on classification of the Kenya baboon. In: The Baboon in Medical Research, Vol. II (eds Vagtborg H, Vagtborg H), pp. 13-22. University of Texas Press, Austin, Texas.

Marshall J, Sugardjito J (1986) Gibbon systematics. In: Comparative Primate Biology, Vol. I: Systematics, Evolution, and Anatomy (eds Erwin J, Swindler DR), pp. 137-185. Alan Liss, New York.

Mays HL, Hill GE (2004) Choosing mates: good genes versus genes that are a good fit. Trends in Ecology \& Evolution, 19, 554-559.

McClelland EK, Naish KA (2007) What is the fitness outcome of crossing unrelated fish populations? A meta-analysis and an evaluation of future research directions. Conservation Genetics, 8 , 397-416.

Muruthi P, Altmann J, Altmann S (1991) Resource base, parity and reproductive condition affect females' feeding time and nutrient intake within and between groups of a baboon population. Oecologia, 87, 467-472.

Nagel U (1973) A comparison of anubis baboons, hamadryas baboons and their hybrids at a species border in Ethiopia. Folia Primatologica, 9, 104-165.

Newman TK, Jolly CJ, Rogers J (2004) Mitochondrial phylogeny and systematics of baboons (Papio). American Journal of Physical Anthropology, 124, 17-27.

Norman GR, Streiner DL (2000) Biostatistics: The Bare Essentials. BC Decker, Hamilton, Canada.
Phillips-Conroy J, Jolly CJ (1981) Sexual dimorphism in two subspecies of Ethiopian baboons (Papio hamadryas) and their hybrids. American Journal of Physical Anthropology, 56, 115-129.

Phillips-Conroy JE, Jolly CJ (1986) Changes in the structure of the baboon hybrid zone in the Awash National Park, Ethiopia. American Journal of Physical Anthropology, 71, 337-349.

Pritchard JK, Stephens M, Donnelly P (2000) Inference of population structure using multilocus genotype data. Genetics, 155, 945-959.

Pujolar JM, Maes GE, Vancoillie C, Volckaert FAM (2005) Growth rate correlates to individual heterozygosity in the European eel Anguilla anguilla L. Evolution, 59, 189-199.

Pusey A, Packer C (1987) Dispersal and philopatry. In: Primate Societies (eds Smuts BB, Cheney DL, Seyfarth RM, Wrangham RW, Struhsaker TT), pp. 250-266. University of Chicago Press, Chicago.

Pusey A, Williams J, Goodall J (1997) The influence of dominance rank on the reproductive success of female chimpanzees. Science, 277, 828-831.

Rieseberg LH (1997) Hybrid origins of plant species. Annual Review of Ecology and Systematics, 28, 359-389.

Roff DA (1992) The Evolution of Life Histories. Chapman \& Hall, New York.

Samuels A, Altmann J (1986) Immigration of a Papio anubis male into a group of Papio cynocephalus baboons and evidence for an anubis-cynocephalus hybrid zone in Amboseli, Kenya. International Journal of Primatology, 7, 131-138.

Samuels A, Altmann J (1991) Baboons of the Amboseli basin: demographic stability and change. International Journal of Primatology, 12, 1-9.

Schillaci MA, Froehlich JW, Supriatna J (2007) Growth and sexual dimorphism in a population of hybrid macaques. Journal of Zoology, 271, 328-343.

Schwarz D, Matta BM, Shakir-Botteri NL, Mcpheron BA (2005) Host shift to an invasive plant triggers rapid animal hybrid speciation. Nature, 436, 546-549.

Scribner KT (1993) Hybrid zone dynamics are influenced by genotype-specific variation in life-history traits: experimental evidence from hybridizing Gambusia species. Evolution, 47, 632-646.

Seddon N, Amos W, Mulder RA, Tobias JA (2004) Male heterozygosity predicts territory size song structure and reproductive success in a cooperatively breeding bird. Proceedings of the Royal Society B: Biological Sciences, 271, 1823-1829.

Setchell JM, Lee PC, Wickings EJ, Dixson A (2002) Reproductive parameters and maternal investment in mandrills (Mandrillus sphinx). International Journal of Primatology, 23, 51-68.

Silk JB (1987) Social behavior in evolutionary perspective. In: Primate Societies (eds Smuts BB, Cheney DL, Seyfarth RM, Wrangham RW, Struhsaker TT), pp. 318-329. University of Chicago Press, Chicago.

Silk JB (2001) Bonnet macaques: evolutionary perspectives on females' lives. In: Model Systems in Behavioral Ecology (ed. Dugatkin LA), pp. 433-452. Princeton University Press, Princeton, New Jersey.

Slate J, Kruuk LEB, Marshall TC et al. (2000) Inbreeding depression influences lifetime breeding success in a wild population of red deer (Cervus elaphus). Proceedings of the Royal Society B: Biological Sciences, 267, 1657-1662.

Stearns SC (1976) Life-history tactics: a review of the ideas. Quarterly Review of Biology, 51, 3-47.

Stearns SC (1992) The Evolution of Life Histories. Oxford University Press, Oxford, UK.

Storz JF, Ramakrishnan U, Alberts SC (2002) Genetic effective size of a wild primate population: influence of current and historical demography. Evolution, 56, 817-829. 
Supriatna J (1991) Hybridization between Macaca maurus and Macaca tonkeana: a test of species status using behavioral and morphogenetic analysis. PhD Dissertation, University of New Mexico.

Supriatna J, Froehlich JW, Erwin JM, Southwick CH (1992) Population habitat and conservation status of Macaca maurus, Macaca tonkeana and their putative hybrid. Tropical Biodiversity, 1, 31-48.

Tung J, Charpentier MJE, Garfield DA, Altmann J, Alberts SC (2008) Genetic evidence reveals temporal change in hybridization patterns in a wild baboon population. Molecular Ecology doi: $10.1111 /$ j.1365-294X.2008.03723.x.

Walters JR, Seyfarth RM (1987) Conflict and cooperation. In: Primate Societies (eds Smuts BB, Cheney DL, Seyfarth RM, Wrangham RW, Struhsaker TT), pp. 306-317. University of Chicago Press, Chicago.

Watanabe K, Matsumura S (1991) The borderlands and possible hybrids between three species of macaques, $M$. nigra, $M$. nigrescens, and M. hecki, in the northern peninsula of Sulawesi. Primates, 32, 365-369.

Watanabe K, Lapasere H, Tantu R (1991a) External characteristics and associated developmental changes in two species of Sulawesi macaques, Macaca tonkeana and Macaca hecki, with special reference to hybrids and the borderlands between species. Primates, 32, 61-76.

Watanabe K, Matsumura S, Watanabe T, Hamada Y (1991b) Distribution and possible intergradation between Macaca tonkeana and Macaca ochreata at the borderland of the species in Sulawesi. Primates, 32, 369-385.

Wildman DE, Bergman TJ, al-Aghbari A et al. (2004) Mitochondrial evidence for the origin of hamadryas baboons. Molecular Phylogenetics and Evolution, 32, 287-296.

Williams-Blangero S, Blangero J (1995) Heritability of age at first birth in captive olive baboons. American Journal of Primatology, $37,233-239$.
Zinner D, Krebs E, Schrod A, Kaumanns W (2005) Early sexual maturity in male hamadryas baboons (Papio hamadryas hamadryas) and its reproductive implications. American Journal of Physical Anthropology, 129, 584-590.

Marie Charpentier is interested in the study of mating systems, kin relationships and social structure in primates. Jenny Tung is a graduate student interested in the evolutionary genetics of wild populations, particularly the functional effects of genetic variation on fitness-related traits. Susan C. Alberts and Jeanne Altmann are Co-directors of the Amboseli Baboon Research Project. Their research program seeks to identify demographic, environmental, endocrine and genetic correlates of and sources of variance in fitness components in a natural population of mammals.

\section{Supplementary material}

The following supplementary material is available for this article:

Table S1 Predictor variables used in the analyses of maturation

This material is available as part of the online article from:

http://www.blackwell-synergy.com/doi/abs /

10.1111/j.1365-294X.2008.03724.x

(This link will take you to the article abstract).

Please note: Blackwell Publishing are not responsible for the content or functionality of any supplementary materials supplied by the authors. Any queries (other than missing material) should be directed to the corresponding author for the article. 